\title{
Endoscopic submucosal dissection for remnant rectal neoplasm after ileal pouch-anal anastomosis for ulcerative colitis
}

Restorative proctocolectomy with stapled ileal pouch-anal anastomosis (IPAA) has been a routinely performed surgical procedure for ulcerative colitis (UC); however, tumor development from the remnant rectal mucosa is problematic $[1,2]$. Here, we report a case of successful endoscopic submucosal dissection (ESD) for a neoplasm arising from the remnant rectal mucosa after proctocolectomy for refractory UC ( $\triangleright$ Video 1 ).

A 64-year-old woman who underwent restorative proctocolectomy with stapled IPAA for refractory UC 16 years ago was diagnosed with a sessile neoplasm, measuring $40 \mathrm{~mm}$ in diameter ( $>$ Fig. 1 a). Endoscopic submucosal dissection (ESD) was proposed as a total excisional biopsy for histopathological assessment, including background mucosa.

The rectal lumen was nonpliable owing to the surgical anastomotic suture and diffuse submucosal fibrosis, and therefore, unlike in the usual rectal ESD procedure, a vertical approach to the muscularis was required. For this we used a multi-bending gastroscope (GIF2TQ260M; Olympus Medical Systems, Tokyo, Japan), which offered a tangential approach to the submucosal space during a retroflex maneuver ( $\downarrow$ Fig. $\mathbf{1}$ b). Dissection using endo-cut mode was effective, even for the severe fibrotic submucosa. Successful en bloc resection was

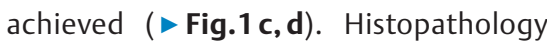
revealed a tubulovillous adenoma with R0 resection (> Fig. 2 ). Immunohistochemically, the tumor was negative for p53, and no dysplastic lesion was found in the background mucosa. Thus, the lesion was diagnosed as a sporadic rectal adenoma with curative resection.

To our knowledge, this is the first report describing tumorigenesis, including sporadic neoplasm, and a detailed technique of rectal ESD after proctocolectomy for UC. Although colorectal ESD for patients with UC is usually difficult because of submucosal fibrosis and adi-

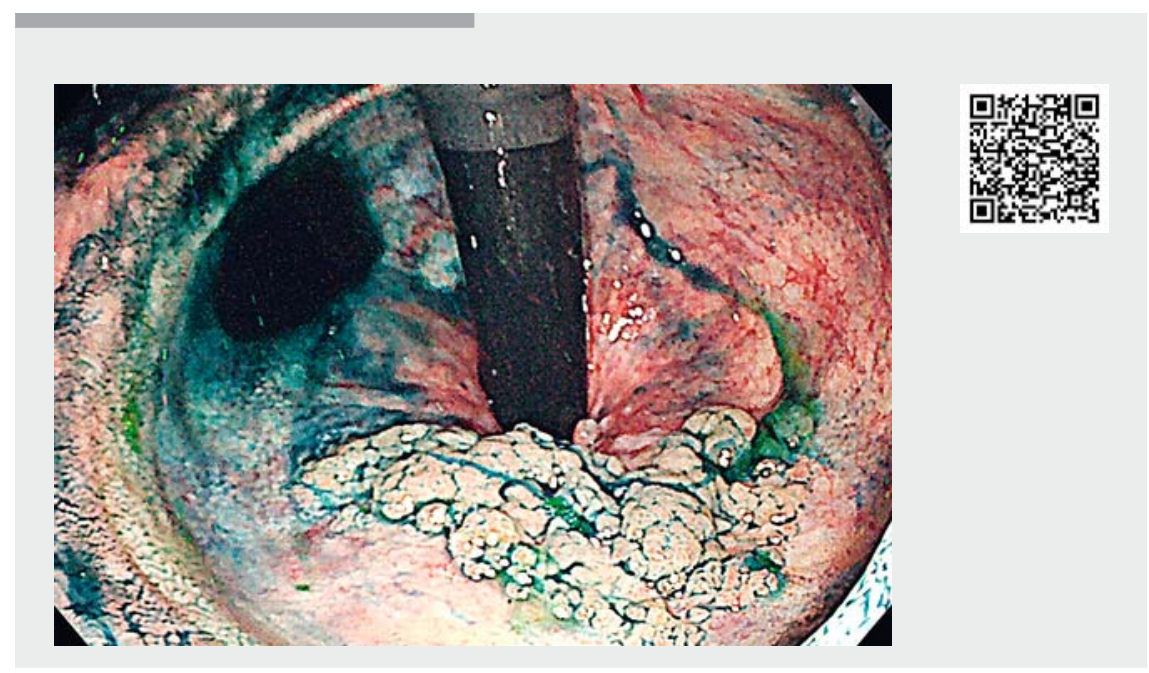

$\checkmark$ Video 1 Endoscopic submucosal dissection for a neoplasm arising from a remnant rectal mucosa after proctocolectomy for ulcerative colitis.
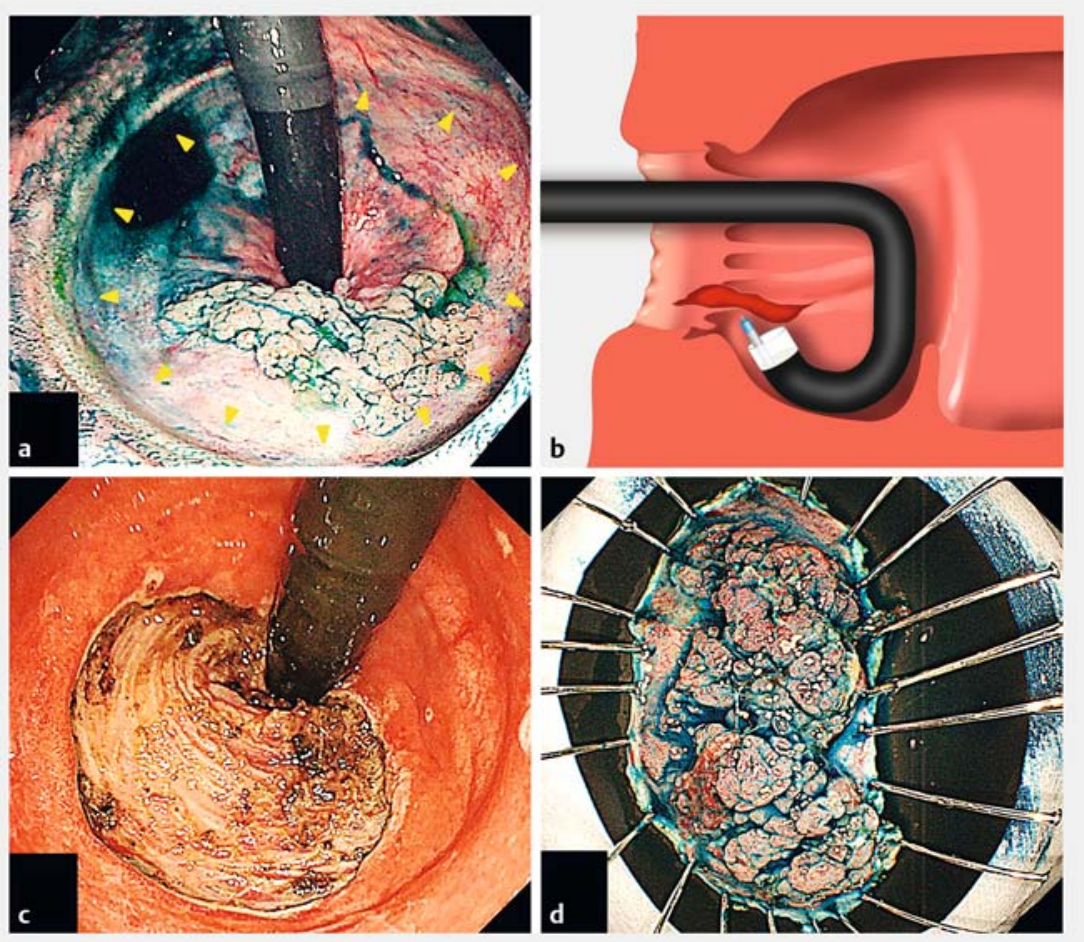

- Fig. 1 The sequence of endoscopic submucosal dissection (ESD). a Endoscopic retroflex view of the lesion. Arrow head shows anastomotic suture line. $\mathbf{b}$ The schema of tangential approach using a retroflex maneuver with multi-bending function. c The ulcer bed after performing ESD. $\mathbf{d}$ The resected specimen. 


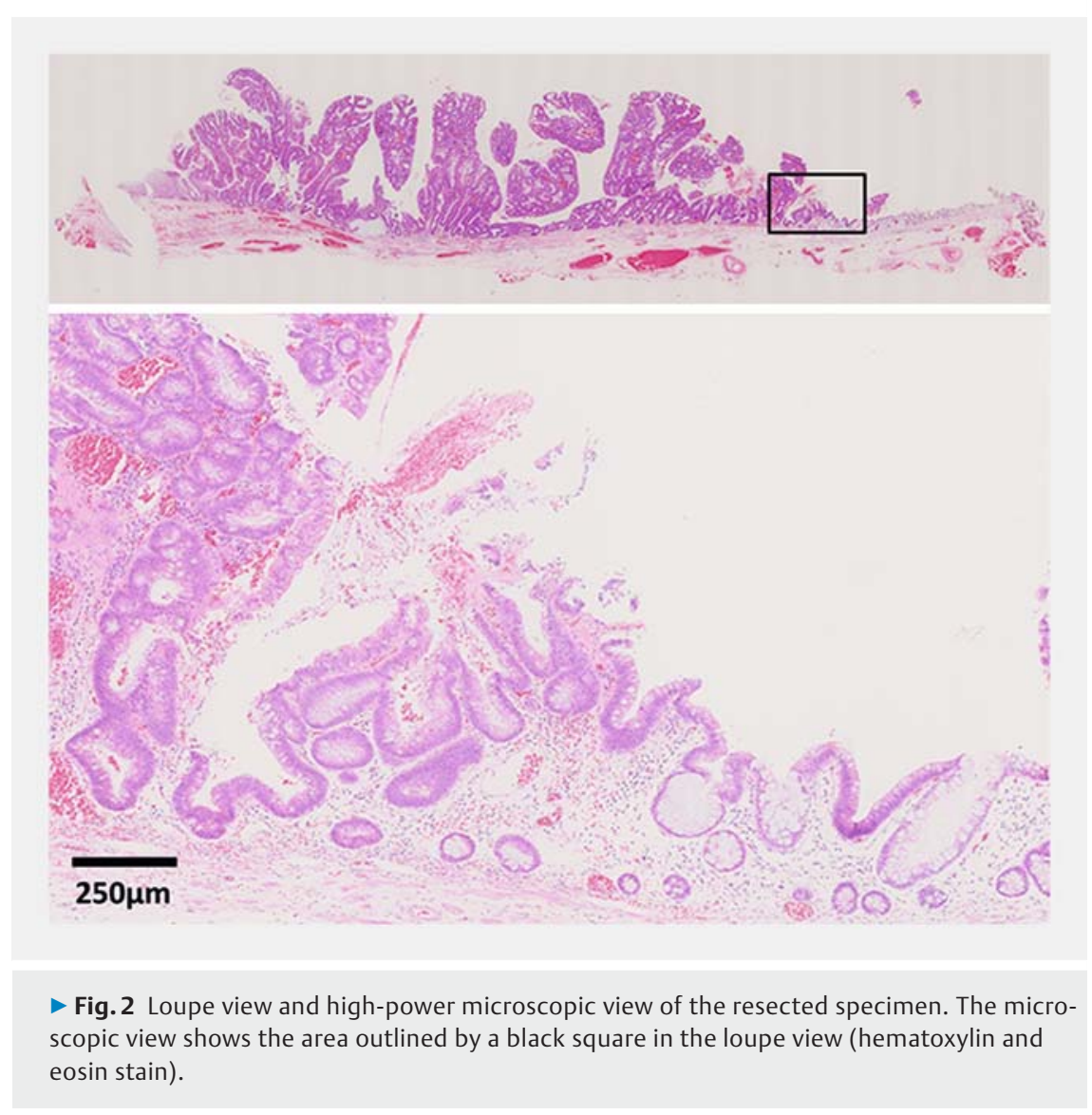

pose tissue deposition [3], successful ESD can help to avoid invasive surgery and preserve the quality of life. ESD is considered useful as a precise and minimally invasive diagnostic procedure for neoplastic lesions in patients with UC, even after proctocolectomy.

Endoscopy_UCTN_Code_TTT_1AQ_2AD
Competing interests

None

The authors

Shunsuke Yoshii, Shinichiro Shinzaki, Yoshito Hayashi, Yoshiki Tsujii, Munehiro Ashida, Hideki lijima, Tetsuo Takehara

Department of Gastroenterology and Hepatology, Osaka University Graduate School of Medicine, Osaka, Japan
Corresponding author

\section{Tetsuo Takehara, MD, PhD}

Department of Gastroenterology and Hepatology, Osaka University Graduate School of Medicine, Osaka, Japan Fax: +81-6-68793629

takehara@gh.med.osaka-u.ac.jp

\section{References}

[1] Annese V, Beaugerie L, Egan L et al. European evidence-based consensus: inflammatory bowel disease and malignancies. J Crohns Colitis 2015; 9: 945-965

[2] Shergill AK, Lightdale JR, Bruining DH et al. The role of endoscopy in inflammatory bowel disease. Gastrointest Endosc 2015; 81: $1101-1121$

[3] Suzuki N, Toyonaga T, East JE. Endoscopic submucosal dissection of colitis-related dysplasia. Endoscopy 2017; 49: 1237-1242

\section{Bibliography}

DOI https://doi.org/10.1055/a-0950-9501

Published online: 30.7.2019

Endoscopy 2019; 51: E406-E407

(c) Georg Thieme Verlag KG

Stuttgart · New York

ISSN 0013-726X

\section{ENDOSCOPY E-VIDEOS \\ https://eref.thieme.de/e-videos}

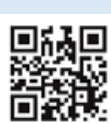

Endoscopy E-Videos is a free access online section, reporting on interesting cases and new techniques in gastroenterological endoscopy. All papers include a high quality video and all contributions are freely accessible online.

This section has its own submission website at

https://mc.manuscriptcentral.com/e-videos 